\title{
A Tablet-Based Multimedia Education Tool Improves Provider and Subject Knowledge of Inhaler Use Techniques
}

\author{
Aaron M Mulhall MD, Muhammad A Zafar MD, Samantha Record PharmD, \\ Herman Channell LPN, and Ralph J Panos MD
}

\begin{abstract}
BACKGROUND: Although inhaled medications are effective therapies for COPD, many patients and providers use them incorrectly. METHODS: We recruited providers who prescribe inhalers or teach inhaler technique and assessed their use of metered-dose inhalers (MDIs), various dry powder inhalers (DPIs), and Respimat using predefined checklists. Then they watched tablet-based multimedia educational videos that demonstrated correct inhaler technique by a clinical pharmacist with teach-back from a patient and were re-evaluated. We also recruited patients with COPD and assessed their use of their prescribed inhalers and then retested them after 3-6 months. Baseline and follow-up respiratory symptoms were measured by the COPD Assessment Test. RESULTS: Fifty-eight providers and 50 subjects participated. For all providers, correct inhaler technique (reported as percentage correct steps) increased after the videos: MDI without a spacer $(72 \%$ vs 97\%) MDI with a spacer (72\% vs $96 \%)$, formoterol DPI (50\% vs $94 \%)$, mometasone DPI (43\% vs 95\%), tiotropium DPI (73\% vs 99\%), and Respimat (32\% vs 93\%) (before vs after, $P<.001$ for all comparisons). Subjects also improved their inhaler use technique after viewing the educational videos: MDI without a spacer (69\% vs $92 \%$ ), MDI with a spacer (73\% vs $95 \%$ ), and tiotropium DPI $(83 \%$ vs $96 \%$ ) (before vs after, $P<.001$ for all comparisons). The beneficial effect of this educational intervention declined slightly for subjects but was durably improved after several months. COPD Assessment Test scores did not demonstrate any change in respiratory symptoms. CONCLUSIONS: A tablet-based inhaler education tool improved inhaler technique for both providers and subjects. Although this intervention did show durable efficacy for improving inhaler use by patients, it did not reduce their respiratory symptoms. Key words: inhalers; education; multimedia; health-care providers; inhaler technique. [Respir Care 2017;62(2):163-171. (C) 2017 Daedalus Enterprises]
\end{abstract}

\section{Introduction}

Inhaled medications are critical for the pharmacologic treatment of COPD. ${ }^{1}$ The most commonly used inhaler

Drs Mulhall, Zafar, and Panos are affiliated with the Divison of Pulmonary, Critical Care, and Sleep Medicine, Cincinnati Veterans Affairs Medical Center and the Division of Pulmonary, Critical Care, and Sleep Medicine, University of Cincinnati College of Medicine, Cincinnati, Ohio. Dr Record is affiliated with the Division of Clinical Pharmacy, Cincinnati Veteran Affairs Medical Center, Cincinnati, Ohio. Mr Channell is affiliated with the Division of Primary Care, Cincinnati Veterans Affairs Medical Center, Cincinnati, Ohio.

This work was supported by the Veterans Health Administration Specialty Care Services, Specialty Care Transformation Initiative: Patient Centered Model for the Management of Chronic Obstructive Pulmonary Disease. The authors have disclosed no conflicts of interest. devices are metered-dose inhalers (MDIs), dry powder inhalers (DPIs), the Respimat soft mist inhaler (SMI), and nebulizers. When used properly, these devices deliver a precise amount of drug with optimal mass median aero-

\footnotetext{
Supplementary material related to this paper is available at http:// www.rcjournal.com.

Dr Mulhall presented a version of this work at the Chest 2015 meeting, held October 24-28, 2015, in Montreal, Canada.

Correspondence: Aaron M Mulhall MD, Division of Pulmonary, Critical Care, and Sleep Medicine, Cincinnati Veterans Affairs Medical Center, 3200 Vine Street. Cincinnati, OH 45220. E-mail: mulhalan@ucmail. uc.edu.
}

DOI: $10.4187 /$ respcare. 05008 


\section{Multimedia ToOl for Inhaler Technique Education}

dynamic diameter to reach sites of biologic action. Errors in inhaler technique compromise drug delivery, reduce clinical efficacy, and increase adverse effects. The proportion of patients with COPD who misuse their inhalers ranges from 26 to $90 \% .^{1-7}$ Factors associated with incorrect use include age, cognitive impairment, number of prescribed inhalers, and inadequate/poor inhaler technique education. ${ }^{8,9}$ Health-care providers' knowledge of correct inhaler use technique is critical for patient education. The percentage of healthcare providers who do not use inhalers correctly is significant (12-98\%) and varies by profession. ${ }^{8,10}$

A variety of instructional modalities can be used to provide inhaler education. Individualized one-on-one coaching is effective, but many patients quickly revert to incorrect techniques. ${ }^{11}$ Multimedia education has grown in popularity over the past decade and is used to demonstrate correct use of MDIs and DPIs (http://www.asthma.org.uk; www.NationalAsthma.org.au; www.admit-online.info; Accessed April 10, 2016).

The aim of this study was to assess the effect of a tabletbased multimedia inhaler education tool on correct inhaler use techniques by health-care providers and veterans with COPD. Our hypothesis was that educational videos viewed individually on tablets will improve correct inhaler technique and reduce patients' respiratory symptoms.

\section{Methods}

\section{Study Design/Participant Selection}

This study was a single-center, prospective, observational, pre- and post-interventional evaluation of healthcare providers and out-patient veterans with COPD at the Cincinnati Veterans Affairs Medical Center (VAMC). Patients were selected at random and were all being seen in the out-patient pulmonary clinic at the Cincinnati VAMC. Only providers who prescribed inhalers and/or provided inhaler education to patients participated. Inclusion criteria were diagnosis of COPD with air-flow limitation confirmed by spirometry, ${ }^{12}$ prescriptions for one or more inhaled medications, and age $\geq 18 \mathrm{y}$. Exclusion criteria included patients not currently prescribed inhaled medications and those with dementia or mild cognitive impairment. This study was approved by the Cincinnati VAMC Research and Development Committee and the University of Cincinnati College of Medicine institutional review board (approval 2014-3275).

\section{Tablet-Based Intervention}

Detailed checklists itemizing the steps for correct inhaler technique were developed for each inhaler through literature and package insert review. The checklists were revised and approved by Cincinnati VAMC clinical pharmacy, respiratory therapy, and pulmonary staff. All inhal-

\section{QUICK LOOK}

\section{Current knowledge}

Inhaled medications are critical for the pharmacologic treatment of COPD. Many patients with COPD have poor inhaler technique, and correct inhaler training by health-care providers is often suboptimal.

\section{What this paper contributes to our knowledge}

A multimedia inhaler education tool improved inhaler use technique by both health-care providers and subjects. After watching the educational videos, subjects maintained a durable improvement in inhaler use technique for several months. This form of multimedia education is easy to use, can be utilized across a spectrum of health-care settings, and can be accessed on multiple technological platforms.

ers on the Cincinnati VAMC formulary were included: MDIs with and without spacer use, formoterol (Foradil) DPI, mometasone (Asmanex) DPI, tiotropium (Spiriva) DPI, and Respimat SMI (see Supplement 1 in the supplementary materials at http://www.rcjournal.com). Three to five-minute inhaler education videos incorporating the checklist steps were created using a standardized script: A clinical pharmacist (SR) reviews correct inhaler technique with a patient (HC). The subject then provides a "teachback" to the pharmacist by repeating the just-demonstrated technique. The videos were loaded onto tablets (Acer Iconia, Acer America, San Jose, California) and identified by an icon of the inhaler. To activate the video, the icon is pressed. Screen settings and volume were adjusted to be seen and heard in a clinic setting (Supplements 2-7).

\section{Provider and Subject Data Collection}

A quantitative scoring system (correct step $=1$ point; incorrect $/$ missed step $=0$ points) based upon the itemized checklists for each device was used to measure inhaler technique. To measure short-term retention for providers, AMM directly observed and assessed inhaler technique for each provider, who then immediately watched the instructional videos and was retested afterward $(\sim 30 \mathrm{~min}$ between the pre- and post-test). Each provider then completed video and demographics surveys.

Subjects were tested for correct technique only for their prescribed inhalers. Then they viewed the videos for those inhalers and were retested in a similar fashion as the providers. At the initial encounter, subjects completed a demographics questionnaire, COPD Health Determinants survey, ${ }^{13}$ and the COPD Assessment Test. ${ }^{14}$ After $3-6$ months, 


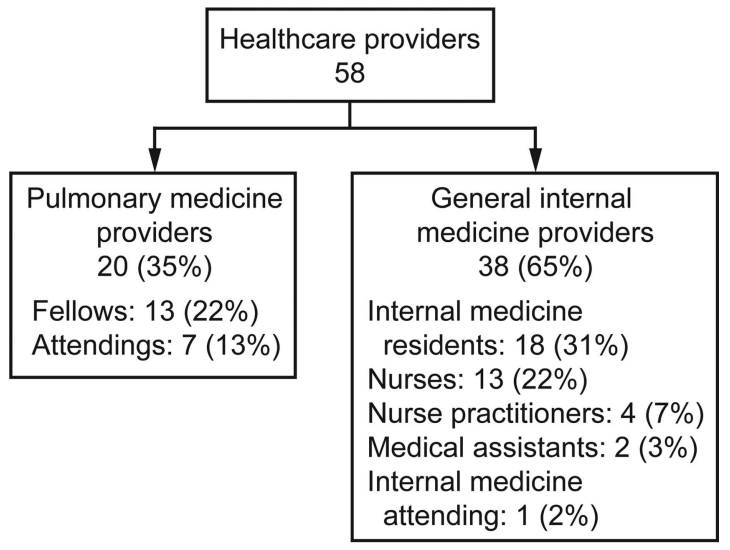

Fig. 1. Health-care provider demographics.

inhaler use was reassessed, and the COPD Assessment Test was repeated.

The primary outcome was inhaler use technique scores. Secondary outcomes were improvement durability over 3-6 months and respiratory symptoms measured by the COPD Assessment Test.

\section{Data Entry and Statistical Analysis}

We entered all data into an Excel (Microsoft, Redmond, Washington) database and verified each record in an independent review of data entry. Mean and SD were calculated for numerical variables. All statistical comparisons were performed using Student's paired $t$ test (SAS 9.2, SAS Institute, Cary, North Carolina). Significant differences were defined as $P<.05$, and the COPD Assessment Test minimal clinically important difference was 2 points. ${ }^{15}$

\section{Results}

\section{Demographics}

Fifty-eight health-care providers (Fig. 1) and 50 veterans participated. Subjects' demographics, clinical characteristics, and pulmonary function studies are presented in Table 1. Forty-seven subjects (94\%) were prescribed multiple inhaled medications, and $41(82 \%)$ utilized multiple inhaler devices: 37 (74\%) MDI and one type of DPI, 2 (4\%) MDI and 2 different types of DPI, and 2 (4\%) MDI and Respimat SMI.

\section{Health-Care Providers' Inhaler Technique}

The proportion of correctly performed steps for each device increased after viewing the videos: MDI without a spacer $(71.3 \pm 18.8 \%$ vs $97.3 \pm 5.35 \%)$, MDI with spacer $(72.2 \pm 16.7 \%$ vs $95.9 \pm 7.8 \%)$, formoterol DPI (49.7 \pm
Table 1. Clinical Characteristics of Subjects With COPD

\begin{tabular}{|c|c|}
\hline Subject Characteristics & Values \\
\hline Age, mean $\pm \mathrm{SD}$ y & $67.7 \pm 9.4$ \\
\hline Male sex, $n(\%)$ & $49(98)$ \\
\hline \multicolumn{2}{|l|}{ Smoking status, $n(\%)$} \\
\hline Current & $17(34)$ \\
\hline Former & $30(60)$ \\
\hline Never & $3(6)$ \\
\hline Number of pack-years smoked, mean $\pm \mathrm{SD}$ & $55.0 \pm 29.5$ \\
\hline \multicolumn{2}{|l|}{ Pulmonary function testing, mean $\pm \mathrm{SD} \%$ predicted } \\
\hline $\mathrm{FEV}_{1} / \mathrm{FVC}(n=50)$ & $53.4 \pm 14.1$ \\
\hline $\mathrm{FEV}_{1}(n=50)$ & $50.9 \pm 18.1$ \\
\hline $\mathrm{FVC}(n=49)$ & $72.1 \pm 18.3$ \\
\hline TLC $(n=45)$ & $108.9 \pm 18.9$ \\
\hline $\mathrm{RV}(n=45)$ & $155.4 \pm 49.3$ \\
\hline $\mathrm{D}_{\mathrm{LCO}}(n=47)$ & $63.6 \pm 21.0$ \\
\hline \multicolumn{2}{|l|}{ Inhalers prescribed, $n(\%)$} \\
\hline Albuterol MDI & $47(94)$ \\
\hline Budesonide/Formoterol MDI & $43(86)$ \\
\hline Tiotropium DPI & $37(74)$ \\
\hline Budesonide/Formoterol MDI + Tiotropium DPI & $35(70)$ \\
\hline Mometasone DPI & $3(6)$ \\
\hline Formoterol DPI & $3(6)$ \\
\hline Albuterol/Ipratropium Respimat SMI & $2(4)$ \\
\hline Spacer use $(n=48)$ & $22(45.6)$ \\
\hline \multicolumn{2}{|l|}{ Co-morbidities, $n(\%)$} \\
\hline $0-1$ comorbidity & $5(10)$ \\
\hline 2-3 comorbidities & $10(20)$ \\
\hline$>3$ comorbidities & $35(70)$ \\
\hline Hyperlipidemia & $29(58)$ \\
\hline Hypertension & $28(56)$ \\
\hline Osteoarthritis & $22(44)$ \\
\hline Coronary artery disease & $15(30)$ \\
\hline Depression & $13(26)$ \\
\hline Diabetes & $12(24)$ \\
\hline Gastroesophageal reflux disease & $10(20)$ \\
\hline Obstructive sleep apnea & $7(14)$ \\
\hline Atrial arrhythmia & $5(10)$ \\
\hline Post-traumatic stress disorder & $4(8)$ \\
\hline Chronic kidney disease & $4(8)$ \\
\hline Alcohol/substance abuse & $4(8)$ \\
\hline Anxiety & $3(6)$ \\
\hline \multicolumn{2}{|l|}{$\begin{array}{l}\text { TLC = total lung capacity } \\
\text { RV }=\text { residual volume } \\
\mathrm{D}_{\mathrm{LCO}}=\text { diffusing capacity for carbon monoxide } \\
\text { MDI = metered-dose inhaler } \\
\mathrm{DPI}=\text { dry powder inhaler } \\
\text { SMI = soft mist inhaler }\end{array}$} \\
\hline
\end{tabular}

$24.0 \%$ vs $94.3 \pm 7.8 \%)$, mometasone DPI $(43.1 \pm 24.9 \%$ vs $94.7 \pm 10.1 \%)$, tiotropium DPI (73.4 $\pm 23.9 \%$ vs $98.8 \pm 4.9 \%)$, albuterol/ipratropium Respimat SMI (31.9 $\pm 17.1 \%$ vs $93.1 \pm 9.4 \%$ ) (before vs after, $P<.001$ for all comparisons) (Fig. 2). In a subgroup analysis, the findings were similar when grouped by specialty: pulmonologists: MDI without a spacer $(66.5 \pm 21.3 \%$ vs $97.5 \pm 5.5 \%, P<.001)$, 

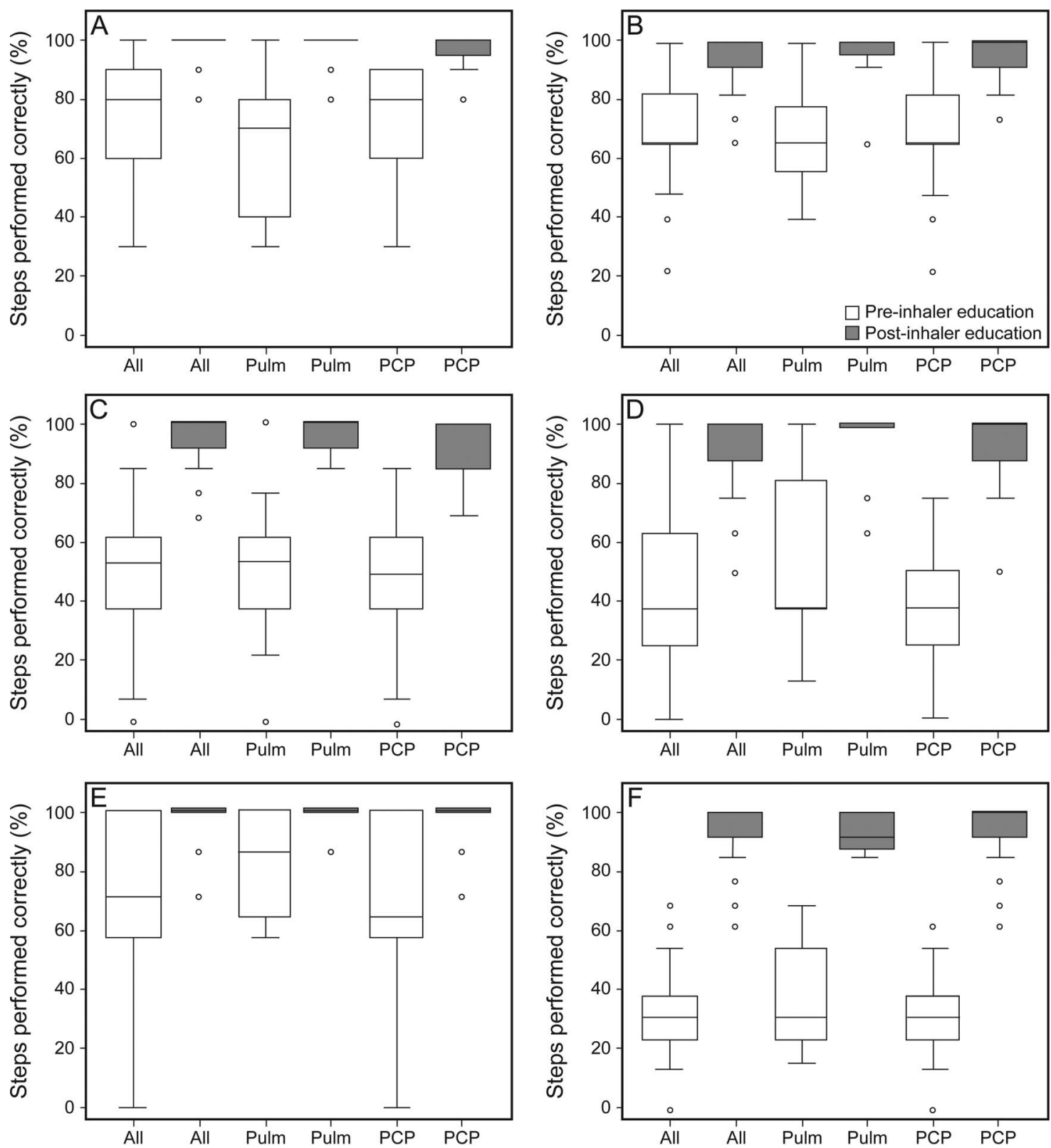

Fig. 2. Health-care providers' inhaler technique scores. Results are displayed in 3 categories: all providers' test scores ( $N=58)$ before and after inhaler education (all), all pulmonary providers' (Pulm) test scores $(n=20)$ before and after inhaler education, and all primary care providers' (PCP) test scores $(n=38)$ before and after inhaler education. Each panel shows inhaler education scores for the following devices: metered-dose inhaler without a spacer (A), metered-dose inhaler with spacer (B), formoterol dry powder inhaler (C), mometasone dry powder inhaler (D), tiotropium dry powder inhaler $(E)$, and Respimat soft mist inhaler $(F)$. Boxes represent first and third quartiles, and center lines denote the median. Whiskers are the highest and lowest values within $3 / 2$ times the interquartile range. Circles show outliers.

MDI with spacer use $(70.9 \pm 15.4 \%$ vs $96.8 \pm 7.7 \%, P<.001)$, formoterol DPI $(51.3 \pm 20.9 \%$ vs $95.4 \pm 5.7 \%, P<.001)$, mometasone DPI $(52.8 \pm 27.4 \%$ vs $96.9 \pm 9.7 \%, P<$ $.001)$, tiotropium DPI $(81.4 \pm 18.1 \%$ vs $99.3 \pm 3.1 \%$, $P<.001)$, albuterol/ipratropium Respimat SMI $(37.3 \pm 18.2 \%$ vs $93.9 \pm 6.3 \%, P<.001)$; primary care providers: MDI without a spacer $(74.0 \pm 16.8 \%$ vs $97.1 \pm 5.2 \%)$, MDI with spacer use $(72.9 \pm 17.5 \%$ vs
$95.4 \pm 7.9 \%)$, formoterol DPI $(48.6 \pm 26.1 \%$ vs $93.6 \pm 9.0 \%)$, mometasone DPI $(38.1 \pm 22.3 \%$ vs $93.6 \pm 10.3 \%)$, tiotropium DPI $(69.2 \pm 25.6 \%$ vs $98.5 \pm 5.6 \%)$, albuterol/ipratropium Respimat SMI $(29.1 \pm 16.0 \%$ vs $92.7 \pm 10.7 \%)$ (before vs after, $P<.001$ for all comparisons). Pulmonary and primary care providers had similar scores for correct inhaler use for all devices both before and after viewing the instructional videos (data not shown.). 
Table 2. Practice Patterns of Health-Care Providers Who Prescribe Inhalers and/or Teach Inhaler Technique

\begin{tabular}{lc}
\hline \hline \multicolumn{1}{c}{ Provider Characteristics } & $n(\%)$ \\
\hline Practice setting & \\
All out-patient & $9(19)$ \\
Most out-patient and some in-patient & $4(9)$ \\
Most in-patient and some out-patient & $23(50)$ \\
All in-patient & $10(22)$ \\
Cases of COPD and asthma encountered/month & \\
None & $1(2)$ \\
$1-5$ & $4(9)$ \\
$6-10$ & $8(17)$ \\
$11-20$ & $13(28)$ \\
$>20$ & $20(44)$ \\
Percentage of patients who use inhalers & \\
$<25 \%$ & $4(9)$ \\
$25-50 \%$ & $16(35)$ \\
$51-75 \%$ & $9(19)$ \\
$>75 \%$ & $17(37)$ \\
Personal/family inhaler use & $11(24)$ \\
Yes & $35(76)$ \\
No & \\
\hline Forty-six health-care providers completed the demographic survey. & \\
\hline
\end{tabular}

The number of health-care providers who performed every step correctly ( $n[\%]$, pre vs post) were: $1(2 \%)$ versus 42 (72\%) for MDI without a spacer, $6(10 \%)$ versus $41(71 \%)$ for MDI with spacer, $1(2 \%)$ versus 29 (50\%) formoterol DPI, 2 (3\%) versus 41 (71\%) mometasone DPI, 19 (33\%) versus $54(93 \%)$ tiotropium DPI, and 0 (0\%) versus $30(52 \%)$ for Respimat SMI. The specific steps most commonly missed included placing the MDI 2 finger widths away from the mouth; not rinsing out the mouth after budesonide/formoterol MDI or mometasone DPI use; device activation for the formoterol DPI and mometasone DPI; and incorrectly loading, priming, and/or activating the Respimat SMI.

After viewing the instructional videos, all 58 health-care providers $(100 \%)$ found the videos helpful and the tabletbased technology easy to use with satisfactory video quality; 57 (98\%) felt that the videos were of appropriate length; $55(95 \%)$ felt the sound quality was appropriate. Of the 46 health-care providers who completed the demographic survey (79\%) (Table 2), 11 (24\%) personally used or had a primary family member who used an inhaler. There was no difference in pre-video inhaler technique scores among health-care providers who had experienced previous personal or family use of inhalers versus those had no experience: MDI without a spacer $(66.0 \pm 23.3 \%$ vs $68.2 \pm 17.7 \%$, $P=.76)$, MDI with spacer use (73.5 $\pm 23.0 \%$ vs $73.16 \pm 16.7 \%, P=.94)$, formoterol DPI (54.0 $\pm 16.0 \%$ vs $40.2 \pm 22.2 \%, P=.10)$, mometasone DPI (43.5 $\pm 32.7 \%$ vs $38.7 \pm 22.7 \%, P=.60)$, tiotropium DPI $(80.5 \pm 19.6 \%$ vs $68.1 \pm 24.2 \%, P=.14$ ), and albuterol/ipratropium Re-
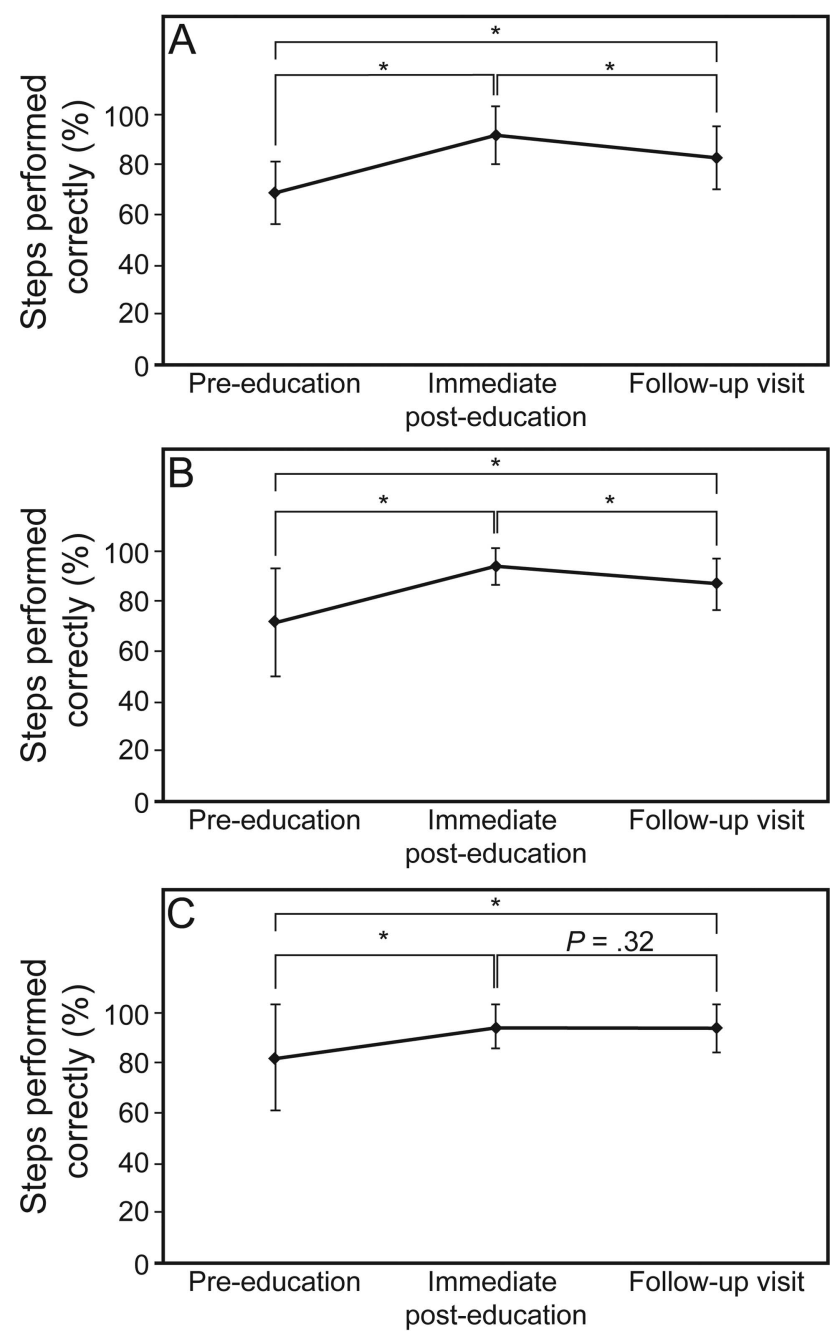

Fig. 3. Subjects' inhaler technique scores. Mean \pm SD percentage of steps performed correctly before inhaler education, immediately after inhaler education, and at follow-up (mean 4.69 months). Inhaler technique scores are for the following devices: metereddose inhaler without a spacer (A) $(n=33)$, MDI with a spacer (B) $(n=32)$, and tiotropium dry powder inhaler (C) $(n=37) .{ }^{*}, P<.001$.

spimat SMI $(24.4 \% \pm 16.6$ vs $32.5 \% \pm 18.2 \%, P=.21)$ (experience vs no experience, $P$ value).

\section{Subjects' Inhaler Technique and Symptoms}

Similar to the health-care providers, subjects improved their inhaler use technique after viewing the educational videos (Fig. 3, A-C): MDI without a spacer (68.8 $\pm 12.4 \%$ vs $91.6 \pm 11.7 \%)$, MDI with spacer use $(72.5 \pm 21.6 \%$ vs $95.4 \pm 7.3 \%)$, and tiotropium DPI $(83.4 \pm 21.8 \%$ vs $96.2 \pm 9.3 \%$ ) (before vs after, $P<.001$ for all comparisons). Relatively few subjects were prescribed formoterol DPI $(n=3)$, mometasone DPI $(n=3)$, and Respimat SMI $(n=2)$, and their pre- and post-education scores did not change. 


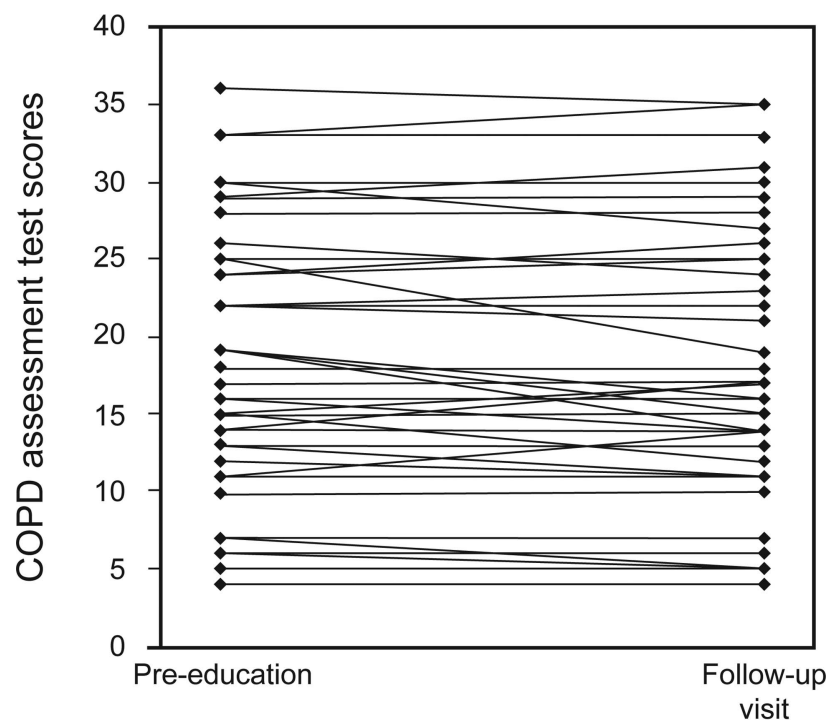

Fig. 4. COPD assessment test scores before inhaler education and at follow-up. Graph displays each subject's $(N=50)$ score before the multimedia intervention and at follow-up (mean 4.69 months). The minimally clinically important difference is a change of 2 points. ${ }^{15} P=.11$ between pre- and post-education.

The subjects were retested after $4.7 \pm 2.1$ months. Although all follow-up inhaler technique scores decreased compared with the immediate post-test results, they were still better than the pre-education test scores for the MDI without a spacer $(68.8 \pm 12.4 \%$ vs $82.7 \pm 12.6 \%, P<.001)$ and MDI with spacer inhalers $(72.5 \pm 21.6 \%$ vs $88.3 \pm 10.6 \%, P<.001$ ) (before vs follow-up, $P$ value (Fig. 3). The tiotropium DPI had follow-up inhaler technique scores that were to the same as the immediate posteducation scores and remained elevated compared with pre-education scores $(83.4 \pm 21.8 \%$ vs $96.5 \pm 5.4 \%$, $P<.001$ ) (immediate vs follow-up, $P$ value). The steps most commonly missed by the patients were placing the MDI 2 finger widths away from the mouth and not rinsing out the mouth after budesonide/formoterol MDI or mometasone DPI use.

COPD Assessment Test scores did not change (17.4 \pm 8.3 vs $17.0 \pm 8.3, P=.11$ ) (before vs follow-up, $P$ value) and did not achieve the minimal clinically important difference $^{15}$ (Fig. 4). There was no clear correlation between inhaler technique retention and symptom improvement.

\section{Subjects' Survey Results}

All 50 subjects completed a questionnaire based upon the COPD Health Determinants survey. ${ }^{13}$ Ninety-two percent of subjects received all of their care at the Cincinnati VAMC. Thirty-seven (74\%) reported that they took their inhalers as prescribed, and $34(68 \%)$ previously received inhaler use instruction. One-fifth of subjects were unsure how/when to use their inhalers. One quarter of subjects regularly questioned whether their inhaler was working properly. Subjects did not take their inhalers as prescribed for numerous reasons: forgetfulness $(26 \%)$, adverse effects $(18 \%)$, saving medications for later $(16 \%)$, medication did not work quickly enough (14\%), medication had to be taken too frequently (12\%), medications had little/no effect (10\%), embarrassment (8\%), medication not needed $(8 \%)$, and concerns for addiction (4\%). When subjects had difficulty breathing, 22 (44\%) took extra puffs of their inhaler, and 22 (44\%) used their inhaler more frequently. Fifteen $(30 \%)$ took oral steroids or antibiotics when short of breath. Thirty-two subjects (64\%) did nothing when they experienced respiratory distress, whereas only $1(2 \%)$ reported never having dyspnea.

All 50 subjects completed the post-video survey; 50 (100\%) felt the tablet-based technology was easy to use, the video quality was adequate, and the videos were of appropriate length, and 49 (98\%) found the sound quality sufficient and the videos helpful.

\section{Discussion}

This study shows that tablet-based inhaler education improves correct inhaler use technique by providers in the short term regardless of specialty or previous personal or family member inhaler use. There were no differences in inhaler use technique between pulmonologists and primary care providers either before or after viewing the videos, but both groups had better technique after the educational intervention. This tablet-based educational tool also improved inhaler use by patients with COPD, which was durable over several months. Despite better inhaler use technique, subjects' respiratory symptoms did not improve.

Health-care providers and patients are confronted by a myriad of devices for the delivery of respiratory medications, each of which has a unique and complex technique for correct use. For patients to learn how to use their inhalers correctly, education should be provided by healthcare providers who are proficient in using inhalers. ${ }^{3,10,16}$ Unfortunately, provider inhaler knowledge is often suboptimal and varies by specialty and level of training (pharmacy, respiratory therapy, house staff, and attending physicians). ${ }^{8}, 10,17-19$ Provider inhaler knowledge is not only important for patient education when initially prescribing inhalers but is critical in the selection of devices that might best suit an individual patient to improve their opportunity for correct use and to identify inhaler technique errors in patients with poorly controlled COPD. ${ }^{10,20}$

Incorrect inhaler technique by patients occurs in up to $90 \%$ of patients with COPD. ${ }^{1,2,5-7,11,21}$ Correct inhaler technique is critical in the management of COPD because inhaled drug effectiveness requires appropriate delivery to the correct anatomic location for maximal physiologic ben- 


\section{Multimedia ToOl for Inhaler Technique Education}

efit. Unlike pills or injections, inhaler use requires a complex series of actions to achieve optimal use and medication delivery. Patients with COPD are often older and can have cognitive or memory impairments that contribute to incorrect inhaler technique. ${ }^{9}$ Further, there are multiple different types of inhalers for respiratory medications, and each has a unique delivery technique. ${ }^{22}$

Providing patients with inhaler education before initiation of therapy is critical, but written instruction alone is often inadequate. ${ }^{23}$ Verbal education with assessment of inhaler technique followed by re-assessment of correct technique at subsequent visits improves inhaler technique.,9,24 Patients who receive inhaler education at regular intervals make fewer mistakes in inhaler technique compared with those who only receive instruction at the time of prescription. ${ }^{25}$ As previously noted, in our study, there was no improvement in the subjects' clinical symptoms over a long-term follow-up period. Potential reasons for the lack of symptomatic improvement include: (1) receiving inhaler education at one interval instead of frequent evaluations, and (2) the fact that $70 \%$ of our subjects were receiving "maximal inhaler therapy" with budesonide/formoterol MDI + tiotropium DPI. These subjects' respiratory symptoms may not be as responsive to inhaled medication but may improve with non-inhaler treatments, such as pulmonary rehabilitation and pursed lip breathing.

Both the Global Initiative for Chronic Obstructive Lung Disease (GOLD) and the National Institute for Health and Care Excellence (NICE) recommend inhaler education and device training when a patient is prescribed a new inhaler and during each subsequent patient encounter (http://gold copd.org/; https://www.nice.org.uk/guidance/cg101; Accessed April 5, 2016). Despite these recommendations, Lavorini et $\mathrm{al}^{21}$ found that $25 \%$ of subjects did not receive any verbal instruction when prescribed an inhaler. We found that 16 (32\%) of our subjects reported never having any inhaler education. A previous survey study of 493 veterans with a diagnosis of COPD showed that $92(19 \%)$ did not recall any inhaler education. ${ }^{12}$

With advancements in information technology, multimedia techniques have been adapted for patient and provider education. The use of tablet-based patient education is effective for patient self-management of chronic diseases and to teach patients physical therapy and pulmonary rehabilitation exercises. ${ }^{26-28}$ Potential benefits of multimedia patient inhaler education include individualized information using a wide range of visual and auditory formats that are viewable in diverse settings, personalized inhaler instruction specific for a patient's devices, selfeducation empowering patients to be more involved in their COPD management, and the ability to review and replay videos when and where repeat education is needed or when questions arise. Videos on tablets or smart phones tend not to be misplaced or discarded, as frequently occurs with paper instructional materials, and deliver information that can easily be shared across a large patient population through internet downloads. ${ }^{29}$ Savage and Goodyer ${ }^{30}$ compared inhaler education delivered by either the manufacturer's paper information leaflet or a multimedia touchscreen computer for 105 subjects with asthma who had been prescribed pressurized MDIs. Inhaler technique scores improved by $44 \%$ in the multimedia group compared with only $19 \%$ in the print-based group $(P<.05)$. We were unable to reproduce these findings because our study design did not include a comparative control group receiving conventional inhaler education (eg, receiving no inhaler education or reading a package insert).

There are a number of strengths to our study. This study evaluates an education tool for both health-care providers and subjects. The same investigator evaluated every healthcare provider and subject before and after education to avoid inter-observer variability. Testing health-care providers and subjects at the time of study enrollment limited bias because they had no prior notification of the study, and the investigators had no prior knowledge of their inhaler education. Last, our tablet-based intervention can easily be accomplished in clinical practice.

Our study does also have some limitations. Although predefined inhaler technique checklists were used, evaluating some steps of inhaler device use can be subjective. For example, emptying air out of the lungs followed by a forceful inhalation, are common steps for almost every inhaler but can only be subjectively evaluated. The first author of this manuscript (AMM) served many roles in this study, in particular the assessment of inhaler technique for all subjects and providers. Having an individual rater of inhaler technique can be a source of bias because that person will know whether the subject was pre- or postinhaler education. In retrospect, the study design could have been stronger by either (1) blinding the assessor to the subject's inhaler education status or (2) having a second rater, therefore enabling reporting of the inter-rater reliability of the assessments. This study was conducted at a single institution, and we cannot exclude any selection bias. The subjects recruited for our study make up a very specific subgroup of patients, veterans with COPD. Thus, the results of the study may differ for civilians in the community with COPD or for groups of patients with other obstructive respiratory disorders. Last, provider knowledge of correct inhaler technique may not translate into the ability to teach patients to use their inhalers correctly.

Another potential limitation is that we did not test respiratory therapists' inhaler technique. They are often primarily responsible for inhaler education in the in-patient, and sometimes in the out-patient, setting. When compared with other providers, respiratory therapists have the highest inhaler knowledge scores and the best inhaler technique. ${ }^{10,16,31,32} \mathrm{~A}$ recent study by Alismail et al ${ }^{32}$ evaluated 


\section{Multimedia ToOl for Inhaler Technique Education}

the use of inhaler education videos on both written and practical inhaler education tests in 4 groups of providers (respiratory therapists, pharmacists, nurses, and physicians). They found that respiratory therapists have the highest baseline written and practical scores, and their practical scores were the only scores to improve significantly after viewing inhaler education videos. Overall, they found that written and practical scores before and after inhaler education were suboptimal. ${ }^{32}$ Our tablet-based videos could easily be reviewed by respiratory therapists to confirm or improve their baseline inhaler knowledge, or they could provide the videos to patients as another mode of inhaler education.

\section{Conclusions}

We found that most health-care providers and subjects with COPD used inhalers incorrectly. Both pulmonary faculty/fellows and primary care providers had suboptimal inhaler technique. A tablet-based inhaler education tool improved correct inhaler use technique by both health-care providers and subjects. After a single encounter, the beneficial effect of this educational intervention declined slightly for subjects, but improvement was durable for several months. However, subjects' respiratory symptoms did not improve.

Future directions for our pulmonary fellows will include a review of inhaler technique, and viewing of the videos will be part of the incoming pulmonary fellows' orientation "boot camp." These videos can also be used by respiratory therapists with in-patients with COPD and by pharmacists, primary care providers, or specialty teams for out-patients with COPD. Future directions for tablet-based multimedia education include using it for other forms of personalized patient education and self-management, such as insulin education, migration to other technology platforms, such as smart phones, and distribution to healthcare providers and patients at other health-care facilities. There is no current accepted standard inhaler education teaching model. This investigation was an initial study to determine whether these tablet-based videos were effective, and future studies are needed to compare the videos with written or verbal education.

\section{ACKNOWLEDGMENTS}

We thank Mark Arlinghaus of Medical Media Services at the Cincinnati Veterans Affairs Medical Center for directing and filming the videos utilized for our tablet-based education intervention.

\section{REFERENCES}

1. Crompton GK. Inhalation devices. Eur J Respir Dis 1982;63(6):489492.

2. McFadden ER Jr. Improper patient techniques with metered dose inhalers: clinical consequences and solutions to misuse. J Allergy Clin Immunol 1995;96(2):278-283.
3. Crompton GK. New inhalation devices. Eur Respir J 1988;1(8):679680 .

4. Newman SP, Weisz AW, Talaee N, Clarke SW. Improvement of drug delivery with a breath actuated pressurised aerosol for patients with poor inhaler technique. Thorax 1991;46(10):712-716.

5. Fink JB, Rubin BK. Problems with inhaler use: a call for improved clinician and patient education. Respir Care 50(10):1360-1374, 2005; discussion 1374-1375.

6. Wieshammer S, Dreyhaupt J. Dry powder inhalers: which factors determine the frequency of handling errors? Respiration 2008;75(1): 18-25.

7. Rees J. Methods of delivering drugs. Br Med J 2005;331(7515):504506.

8. Basheti IA, Qunaibi EA, Hamadi SA, Reddel HK. Inhaler technique training and health-care professionals: effective long-term solution for a current problem. Respir Care 2014;59(11):1716-1725.

9. Leiva-Fernández F, Leiva-Fernández J, Zubeldia-Santoyo F, GarcíaRuiz A, Prados-Torres D, Barnestein-Fonseca P. Efficacy of two educational interventions about inhalation techniques in patients with chronic obstructive pulmonary disease (COPD). TECEPOC: study protocol for a partially randomized controlled trial (preference trial). Trials 2012;13:64.

10. Hanania NA, Wittman R, Kesten S, Chapman KR. Medical personnel's knowledge of and ability to use inhaling devices: metered-dose inhalers, spacing chambers, and breath-actuated dry powder inhalers. Chest 1994;105(1):111-116

11. Crompton GK, Barnes PJ, Broeders M, Corrigan C, Corbetta L, Dekhuijzen R, et al. The need to improve inhalation technique in Europe: a report from the Aerosol Drug Management Improvement Team. Respir Med 2006;100(9):1479-1494.

12. Pellegrino R, Viegi G, Brusasco V, Crapo RO, Burgos F, Casaburi $\mathrm{R}$, et al. Interpretative strategies for lung function tests. Eur Respir J 2005;26(5):948-968.

13. Mulhall AM, Lach LA, Krzywkowski-Mohn SM, Welge JA, Panos RJ. Therapeutic paralysis in veterans with COPD. Respir Med 2013; 107(10):1547-1557.

14. Jones PW, Harding G, Berry P, Wiklund I, Chen WH, Kline Leidy N. Development and first validation of the COPD Assessment Test. Eur Respir J 2009;34(3):648-654.

15. Kon SS, Canavan JL, Jones SE, Nolan CM, Clark AL, Dickson MJ, et al. Minimum clinically important difference for the COPD Assessment Test: a prospective analysis. Lancet Respir Med 2014;2(3): 195-203.

16. Interiano B, Guntupalli KK. Metered-dose inhalers. Do health care providers know what to teach? Arch Intern Med 1993;153(1):81-85.

17. Burton AJ. Asthma inhalation devices: what do we know? Br Med J 1984;288(6431):1650-1651.

18. Kritikos V, Saini B, Bosnic-Anticevich SZ, Krass I, Shah S, Taylor $\mathrm{S}$, Armour C. Innovative asthma health promotion by rural community pharmacists: a feasibility study. Health Promot J Austr 2005; 16(1):69-73.

19. Kesten S, Zive K, Chapman KR. Pharmacist knowledge and ability to use inhaled medication delivery systems. Chest 1993;104(6):1737-1742.

20. Broeders ME, Vincken W, Corbetta L, ADMIT Working Group. The ADMIT series: issues in inhalation therapy. 7. Ways to improve pharmacological management of COPD: the importance of inhaler choice and inhalation technique. Prim Care Respir J 2011;20(3):338-343.

21. Lavorini F, Magnan A, Dubus JC, Voshaar T, Corbetta L, Broeders $\mathrm{M}$, et al. Effect of incorrect use of dry powder inhalers on management of patients with asthma and COPD. Respir Med 2008;102(4): 593-604.

22. Capstick TG, Clifton IJ. Inhaler technique and training in people with chronic obstructive pulmonary disease and asthma. Expert Rev Respir Med 2012;6(1):91-101. 


\section{Multimedia ToOl for Inhaler Technique Education}

23. Mulhall AM. Practical Guide to Inhaler Use. In: Panos RJ, Eschenbacher WL. A COPD primer. Berlin, Germany: De Gruyter; 2015: 292-311.

24. De Boeck K, Alifier M, Warnier G. Is the correct use of a dry powder inhaler (Turbohaler) age dependent? J Allergy Clin Immunol 1999; 103(5 Pt 1):763-767.

25. Gracia-Antequera M, Morales Suarez-Varela M. An intervention to improve the inhalatory technique of children and adolescents with asthma. Allergol Immunopathol 1999;27(5):255-260.

26. Farmer A, Toms C, Hardinge M, Williams V, Rutter H, Tarassenko L. Self-management support using an Internet-linked tablet computer (the EDGE platform)-based intervention in chronic obstructive pulmonary disease: protocol for the EDGE-COPD randomised controlled trial. Br Med J Open 2014;4(1):e004437.

27. Logie CH, Daniel C, Newman PA, Weaver J, Loutfy MR. A psychoeducational HIV/STI prevention intervention for internally displaced women in Leogane, Haiti: results from a non-randomized cohort pilot study PLoS One 2014;9(2):e89836.

28. Sheehy S, Cohen G, Owen KR. Self-management of diabetes in children and young adults using technology and smartphone applications. Curr Diabetes Rev 2014;10(5):298-301.

29. Lavorini F, Levy ML, Corrigan C, Crompton G, ADMIT Working Group. The ADMIT series: issues in inhalation therapy. 6. Training tools for inhalation devices. Prim Care Respir J 2010;19(4):335-341.

30. Savage I, Goodyer L. Providing information on metered dose inhaler technique: is multimedia as effective as print? Fam Pract 2003;20(5): 552-557.

31. Guidry GG, Brown WD, Stogner SW, George RB. Incorrect use of metered dose inhalers by medical personnel. Chest 1992;101(1):31-33.

32. Alismail A, Song CA, Terry MH, Daher N, Almutairi WA, Lo T. Diverse inhaler devices: a big challenge for health-care professionals. Respir Care 2016;61(5):593-599.

This article is approved for Continuing Respiratory Care Education credit. For information and to obtain your CRCE

(free to AARC members) visit

www.rcjournal.com 